\title{
Использование анализа экономической добавленной стоимости при подготовке компании к росту продаж: взгляд практика
}

\author{
Ширкалина O.C. ${ }^{19}$
}

В условиях интенсивного развития экономики в период возобновления промышленного роста в России очевидно, что многие предприятия стремятся $\kappa$ росту продаж, к освоению больщей доли рынка. При этом ориентация на потребителя диктует инновачионные подходы $\kappa$ производству, контролю качества. Все это требует вложения капиталов. В свою очередь, прогнозируемый уровень отдачи от вложенного капитала говорит о целесообразности инвестиций. Необходимо быстро реагировать на рыночную конъюнктуру, четко понимать влияние всех факторов и оперативно принимать решения о том, каким образом, за какое время и какими ресурсами будет достигнута цель - увеличение объема продаж.

Рост продаж - это один из признаков динамичного развития бизнеса и, как правило, он не является стихийным процессом, а есть результат комплекса мероприятий, направленных на стабилизацию и укрепление позиций на рынке. Как проводить анализ планируемого роста с применением финансовых показателей на современном уровне? Какие подходы необходимы в реальной российской производственной компании, чтобы оценка возможного роста соответствовала современным принципам финансового анализа?

\section{Рост продаж: план мероприятий}

Прежде всего необходимо четкое понимание того, за счет чего возможен рост продаж и где могут быть ограничения такого роста, а также какие возможные риски могут сопутствовать этому процессу. Предпосылками роста продаж могут быть:

- вхождение в рынок инновационного продукта, имеющего исключительные свойства, отличающие его от конкурирующих аналогов;

- осуществление мероприятий, стимулирующих увеличение продаж (проведение промо-акций, снижение цены, фокус на продаже взаимодополняющих продуктов, когда рост продаж одного продукта влечет за собой рост продаж другого, и т.д.);

- непрерывное совершенствование навыков продаж сотрудников служб маркетинга и сбыта;

- расширение дилерских сетей;

- и т.д.

Очевидно, что рост продаж - это результат реализации определенной стратегии компании, максимально учитывающей изменения или постоянство ситуации на рынке.

19 Десятилетний опыт работы в сфере экономики и финансов крупных промышленных предприятий, в рамках ответственности — процессы бюджетирования, оперативного планирования, прогнозирования, обоснования инвестиций, анализа деятельности, разработки принципов учета и отчетности , внедрения ЕRР-систем. 
Когда мы говорим об определенной стратегии компании, мы подразумеваем разработку, утверждение и пошаговое осуществление программы мероприятий, которое в итоге приводит к сбалансированной готовности всех подразделений компании к увеличению уровня продаж.

Во-первых, это готовность производственной базы - выявление узких мест производства, расчет необходимых мощностей и сравнение их с существующими. В случае недостаточности имеющихся производственных мощностей необходима разработка мероприятий по расширению производственной базы (покупка или аренда оборудования и площадей).

Во-вторых, готовность вспомогательных служб, которая заключается в обеспечении надежной бесперебойной работы оборудования в условиях максимальной загрузки, а также своевременном и быстром осуществлении его переналадки.

В-третьих, готовность логистических служб, состоящая в возможности гибкой и оперативной адаптации к увеличению плотности материальных потоков. Службы снабжения должны провести работу по обзору поставщиков на предмет возможности поставок в увеличенном объеме. Службы транспорта и складирования должны оценить возможности имеющихся технических средств и складов под размещение возросшего количества запасов сырья и материалов, готовой продукции.

Главным условием для обеспечения готовности всех подразделений является тесное сотрудничество маркетинговой и сбытовой служб с центром НИОКР, производственно-технологическим блоком и службой логистики, а также с финансовым блоком, особенно с сектором бюджетирования.

Именно бюджет, предусматривающий всю динамику развития, отвечает на вопрос, какой ценой и за какое время в действительности возможно будет достигнуть цели - роста объема продаж.

Бюджет служб маркетинга и сбыта должен учитывать не только стоимость содержания этих служб, но и возрастающий объем маркетинговых исследований, расширение торгующих дивизионов, постоянное повышение квалификации персонала, работающего с внешними заказчиками, и т.д. Рекламный бюджет должен учитывать растущие издержки на размещение рекламы в СМИ, промо-акции - скидки, подарки, комбинированные продажи - то есть все, что стимулирует рост продаж. Бюджет инвестиций необходим в том случае, если требуемый рост продаж возможен только с расширением производственной базы или с внедрением систем управления бизнесом (ERPсистем). Соответственно необходим расчет срока окупаемости инвестиций с самым минимальным ростом объема продаж (консервативный вариант, учитывающий риск неоправданности прогнозов), а также четкое определение источника финансирования инвестиций и стоимость привлечения инвестиций, если собственного капитала недостаточно.

В реалиях российского бизнеса необходим и бюджет доходов и расходов в перспективе на три года в разрезе продуктовых линий и каналов сбыта с учетом цен (доходы), издержек (себестоимость) и сумм покрытия (маржинальный доход). Два этих разреза необходимы для понимания, реализация каких продуктов и в каких регионах наиболее рентабельна и перспективна, а сбыт каких из них следует стимулировать мероприятиями и целевым использованием расходов на рекламу и поддержку продаж. На основе бюджета доходов и расходов готовится бюджет поступления и выбытия денежных средств, определяющий необходимый уровень оборотных средств, а также достаточность собственного и размер необходимого к привлечению капитала. Наконец, бюджет баланса, 
раскрывающий изменения в размере основных средств и НМА, запасов, краткосрочной дебиторской и кредиторской задолженности, обязательств по кредитам и займам. Очевидно, что с ростом продаж все эти показатели увеличатся.

Практика компании включает также расчеты определенного набора финансовых показателей, таких как оборачиваемость запасов и дебиторской задолженности, EBITDA (прибыль до вычета процентов, амортизации и налога на прибыль), средневзвешенной стоимости оборотного капитала, экономической добавленной стоимости (EVA), доходности инвестированного капитала (ROCE). Расскажем подробнее об этих показателях.

Расчет оборачиваемости запасов и дебиторской задолженности - это способ оценки риска роста уровня запасов, дебиторской задолженности и замедления скорости их оборачиваемости. Для минимизации таких сопутствующих негативных явлений необходимо:

- во-первых, производственную программу строить по принципу «исключительно под заказ». Для этого оперативное производственное планирование должно осуществляться на основе информации об имеющихся запасах и оперативном плане продаж от службы сбыта. Здесь немаловажно иметь объективную картину о насыщении рынка и его изменяющейся способности осваивать новое предложение производимых компанией товаров;

- во-вторых, организовать работу с поставщиками по принципу «точно вовремя», а также добиваться поставок качественных материалов, комплектующих и услуг с целью максимизации приемки по качеству готовой продукции с первого предъявления. Это не всегда простая задача, однако в условиях роста уровня продаж компании создаются благоприятные условия роста уровня продаж поставщиков, поэтому вывести сотрудничество на максимально взаимовыгодные условия интересно обеим сторонам;

- в-третьих, разработать такую кредитную политику для взаимоотношений с контрагентами, чтобы не было разрывов по поступлению при погашении дебиторской задолженности и выбытиям по погашению кредиторской. То есть сроки отсрочки платежей от покупателей должны быть меньше или равны срокам отсрочки платежей компании поставщикам;

- в-четвертых, разработать такую политику продаж, при которой заказчики будут мотивированы своевременно осуществлять платежи за отгруженную продукцию.

Средневзвешенная стоимость оборотного капитала необходима для того, чтобы в итоге определить экономическую добавленную стоимость (EVA) по результатам деятельности. Это разница между чистой прибылью и средневзвешенной стоимостью инвестированного капитала. Собственники будут считать себя удовлетворенными результатом только в том случае, если доходность их капитала, заработанная в компании, достигла и превысила установленную ими барьерную ставку доходности вложенного в бизнес капитала.

\section{Подготовка к росту продаж в компании «ЭМАльянс»}

Холдинг «Энергомашиностроительный альянс» («ЭМАльянс») является крупнейшим поставщиком на рынке котельного оборудования для теплоэнергетики в России и СНГ. Учитывая факт начала реализации новых инвестиционных программ в энергетике, таких как «Среднесрочная программа развития электроэнергетики на 2006-2010 годы» («Минпромэнерго»), «Инвестиционная программа до 2015 года» (РАО «ЕЭС России»), можно говорить о перспективах, связанных с гарантированным ростом портфеля заказов, что, в 
свою очередь, продиктует компании необходимость рационального планирования программы технического перевооружения, производства, социальных программ.

С увеличением объемов продаж компания может столкнуться с определенными проблемами, поэтому руководству необходимо заблаговременно учесть все финансовые аспекты этого вопроса. В первую очередь это расчет стоимости увеличения продаж и суммы дополнительно привлекаемых ресурсов, направленных на увеличение оборотных активов организации. Также необходимо проанализировать изменения в структуре баланса, связанные с решением вопроса финансирования роста продаж, изменение показателей платежеспособности и финансовой устойчивости. В компании «ЭМАльянс» все начинается с постановки целей. Одной из ключевых целей является динамичный уверенный ежегодный рост объема продаж, другой - рост уровня рентабельности продаж.

Очевидно, что цены диктует рынок, уровень рентабельности диктует собственник, то есть мы ограничены с обеих сторон конкретно обозначенными рамками. Таким образом, компания постоянно находится в состоянии сокращения издержек и минимизации всех видов потерь. Это важно всегда, и особенно в условиях роста бизнеса.

После постановки целей все подразделения начинают согласованную работу по обеспечению готовности компании к увеличению объемов производства и продаж.

Маркетинговые специалисты и эксперты-аналитики исследуют и анализируют рынок энергетического оборудования, нашу потенциально возможную долю на этом рынке. Определяется укрупненный портфель заказов на среднесрочную перспективу - объекты, объемы, цены.

Bсе проекты прогнозируются в части порядка оплаты по возможным контрактам. На основе имеющегося опыта и фактических данных оцениваются возможные размеры сумм авансирования со стороны заказчиков, анализируются наши возможности по предоставлению заказчикам гарантий и обеспечения по ним.

Совместными силами финансисты, экономисты, конструкторы, технологи и производственники укрупнено просчитывают потребности в ресурсах, загрузку производственных мощностей, определяют издержки и суммы покрытия, потребность в оборотном капитале, соотношение собственного и привлеченного капитала, финансовый результат и чистый денежный поток.

Разрабатываются и обосновываются инвестиционные проекты по расширению и модернизации производственной базы. Определяются источники финансирования инвестиций.

Одновременно с этим служба персонала решает проблему повышения потребности квалифицированного производственного персонала и соответственно просчитывает затраты на персонал в связи с ростом объемов производства и продаж.

После таких многоплановых прогнозных расчетов мы определяем суммы дополнительных привлекаемых ресурсов. Мы сотрудничаем с крупными банками, находим возможность кредитования на приемлемых для нас условиях.

При определении политики продаж мы учитываем тот факт, что наша компания занимает монопольное положение на рынке котельного оборудования, это дает нам возможность предъявлять жесткие требования заказчику, при которых, в случае задержки платежей, мы прекращаем отгрузку готовой продукции. Безусловно, такой подход может использоваться только в том случае, когда мы полностью выполняем обязательства по договорам со своей стороны. Так мы имеем возможность контролировать и регулировать уровень дебиторской задолженности. 
Далее более детально рассчитываются бюджеты наиболее крупных проектов, определяется вклад каждого проекта в финансовый результат деятельности компании. После этого формируется бюджет доходов и расходов в разрезе продуктовых линий. После утверждения осуществляется контроль за исполнением бюджета, выявляются отклонения и причины этих отклонений, предпринимаются шаги по выравниванию ситуации в случае значительных отклонений.

Динамику прогноза изменения основных показателей с ожидаемым ростом продаж можно увидеть в таблице 1. Для простоты расчет ведется в ценах текущего года без учета дисконтирования.

Таблица 1. Обзор основных показателей компании с ожидаемым ростом продаж

( млн руб.)

\begin{tabular}{|c|c|c|c|c|c|}
\hline № & Показатель & $\begin{array}{l}\text { Текущ. } \\
\text { год. }\end{array}$ & 1-й год & 2-й год & 3-й год \\
\hline 1 & $\begin{array}{l}\text { Портфель открытых заказов на } \\
\text { начало }\end{array}$ & 7800 & 8300 & 9000 & 8000 \\
\hline 1.1 & $\begin{array}{l}\text { В том числе к производству и } \\
\text { отгрузке }\end{array}$ & 4290 & 4790 & 5490 & 4490 \\
\hline 2 & Поступившие открытые заказы & 5000 & 6000 & 5500 & 5500 \\
\hline 3 & Выручка от продаж & 4500 & 5300 & 6500 & 7000 \\
\hline 4 & $\begin{array}{l}\text { Портфель открытых заказов на } \\
\text { конец }\end{array}$ & 8300 & 9000 & 8000 & 6500 \\
\hline 4.1 & $\begin{array}{l}\text { В том числе к производству и } \\
\text { отгрузке }\end{array}$ & 4790 & 5490 & 4490 & 2990 \\
\hline 5 & Переменные издержки & 3375 & 3869 & 4442 & 4760 \\
\hline 5.1 & Материалы & 1755 & 2051 & 2387 & 2618 \\
\hline 5.2 & Затраты на персонал & 506 & 542 & 707 & 762 \\
\hline 5.3 & Энергоресурсы & 135 & 155 & 177 & 190 \\
\hline 5.4 & Амортизационные отчисления & 34 & 58 & 88 & 95 \\
\hline 5.5 & Услуги & 878 & 987 & 995 & 1000 \\
\hline 5.6 & Прочие & 68 & 77 & 88 & 95 \\
\hline 6 & $\begin{array}{l}\text { Валовая прибыль (маржинальный } \\
\text { доход) }\end{array}$ & 1125 & 1431 & 2058 & 2240 \\
\hline 6.1 & $\begin{array}{l}\text { Валовая прибыль (маржсинальный } \\
\text { доход), \% }\end{array}$ & 25 & 27 & 32 & 32 \\
\hline
\end{tabular}




\begin{tabular}{|c|c|c|c|c|c|}
\hline JP & "КОРПОРАТИВНЫЕ ФИНАНСЫ" & №2 2007 & & & 88 \\
\hline № & Показатель & $\begin{array}{l}\text { Текущ. } \\
\text { год. }\end{array}$ & 1-й год & 2-й год & 3-й год \\
\hline 7 & Условно постоянные издержки & 400 & 420 & 430 & 430 \\
\hline 8 & Проценты за кредит & 97 & 149 & 180 & 127 \\
\hline 9 & Прибыль до налогообложения & 628 & 862 & 1448 & 1683 \\
\hline 9.1 & Чистая прибыль & 477 & 655 & 1101 & 1279 \\
\hline 10 & EBITDA & 793 & 1127 & 1805 & 2000 \\
\hline 10.1 & EBITDA, \% & 17,6 & 21,3 & 27,8 & 28,6 \\
\hline 11 & Запасы на начало & 1285 & 1630 & 1750 & 1620 \\
\hline 11.1 & $\begin{array}{l}\text { ТМЦ (товарно-материальные } \\
\text { ценности) }\end{array}$ & 265 & 330 & 400 & 370 \\
\hline 11.2 & НЗП (незавершенное производство) & 520 & 700 & 750 & 700 \\
\hline 11.3 & ГП (готовая продукция) & 500 & 600 & 600 & 550 \\
\hline 12 & $\begin{array}{l}\text { Дебиторская задолженность на } \\
\text { начало }\end{array}$ & 1700 & 2040 & 2448 & 2693 \\
\hline 13 & $\begin{array}{l}\text { Кредиторская задолженность на } \\
\text { начало }\end{array}$ & 2000 & 2250 & 2600 & 2800 \\
\hline 14 & Оборачиваемость запасов, дней & 59 & 66 & 61 & 53 \\
\hline 15 & $\begin{array}{l}\text { Оборачиваемость дебиторской } \\
\text { задолженности, дней }\end{array}$ & 136 & 139 & 136 & 138 \\
\hline 16 & Рентабельность продаж, \% & 11 & 12 & 17 & 18 \\
\hline 17 & Кредиты и займы & 850 & 1296 & 1497 & 1061 \\
\hline 18 & Всего оборотный капитал & 2985 & 3670 & 4198 & 4313 \\
\hline 19 & $\begin{array}{l}\text { Средневзвешенная стоимость } \\
\text { оборотного капитала }\end{array}$ & 367 & 459 & 569 & 552 \\
\hline 20 & EVA & 110 & 196 & 531 & 727 \\
\hline 21 & $\begin{array}{l}\text { ROCE (рентабельность } \\
\text { используемого капитала) }\end{array}$ & 13 & 15 & 22 & 25 \\
\hline
\end{tabular}

Средневзвешенная стоимость капитала рассчитывается исходя из структуры пассивов (см. таблицу 2) 
Таблица 2. Расчет средневзвешенной стоимости капитала (млн руб.)

\begin{tabular}{|l|r|r|r|r|}
\hline & Текущ.год. & 1-й год & 2-й год & 3-й год \\
\hline Активы & $\mathbf{3 5 5 0}$ & $\mathbf{4 3 9 6}$ & $\mathbf{5 3 9 2}$ & $\mathbf{5 3 3 1}$ \\
\hline Внеоборотные активы & 525 & 650 & 1095 & 1000 \\
\hline Запасы & 1285 & 1630 & 1750 & 1620 \\
\hline Дебиторская задолженность & 1700 & 2040 & 2448 & 2693 \\
\hline Финансовые вложения & 0 & & & \\
\hline Денежные средства & 40 & 76 & 99 & 18 \\
\hline Пассивы & $\mathbf{3 5 5 0}$ & $\mathbf{4 3 9 6}$ & $\mathbf{5 3 9 2}$ & $\mathbf{5 3 3 1}$ \\
\hline Собственный капитал & 700 & 850 & 1295 & 1470 \\
\hline Стоимость собственного капитала & $6 \%$ & $6 \%$ & $6 \%$ & $6 \%$ \\
\hline Долгосрочные обязательства & 0 & 0 & 0 & 0 \\
\hline $\begin{array}{l}\text { Стоимость долгосрочных } \\
\text { обязательств }\end{array}$ & 2850 & 3546 & 4097 & 3861 \\
\hline Краткосрочные обязательства & $11 \%$ & $12 \%$ & $12 \%$ & $12 \%$ \\
\hline Стоимость краткосрочных & & & & 552 \\
\hline обязательств & 467 & 569 & \\
\hline Средневзвешенная стоимость & & & & \\
капитала & & & & \\
\hline
\end{tabular}

Стоимость собственного капитала принимается равной безрисковой ставке доходности по гособязательствам (например, евробонды ) на уровне $6 \%$.

Стоимость привлеченного капитала равна процентной средней ставке привлечения заемных средств.

Очевидно, что с ростом продаж прогнозируется рост рентабельности продаж, EBITDA и рентабельность используемого капитала. Также растет потребность в пополнении оборотного капитала, что осуществляется за счет привлечения кредитов. Средневзвешенная стоимость капитала растет, однако с гораздо меньшими темпами, чем растет чистая прибыль, отсюда и ожидаемая положительная тенденция к росту EVA.

Далее последует роста экономической добавленной стоимости. Возможно, последует разработка программы оптимизации активов (используемого капитала), с целью снизить средневзвешенную стоимость используемого капитала. Здесь очевидно потребуется сфокусироваться на снижении уровня запасов и дебиторской задолженности.

Увеличивая продажи, любая компания естественным образом сталкивается с определенными проблемами и рисками, поэтому важной задачей для акционеров, руководства и специалистов компании является разработка стратегии и четкого плана ее реализации. Этим и занимаются специалисты группы «ЭМАльянс» в 
настоящее время - время начала реализации инвестиционной программы «РАО ЕЭС», т.е. периода роста продаж для нашей компании.

\section{Используемая литература:}

1. Брейли Р., Майерс С. Принципы корпоративных финансов. М.: Олимп Бизнес. 2007 г.

2. Хан Д., Хунгенберг Х.. Планирование и контроль: стоимостноориентированные концепции контроллинга. М.: Финансы и статистика.2005 $\Gamma$. 